\title{
Morphological and Transcriptomic Analysis of Attenuated and Virulent Strains of Phytophthora Infestans
}

Jiafang Liu ( $\square$ 2720638796@qq.com )

Inner Mongolia Agricultural University https://orcid.org/0000-0002-2860-4434

Lei Li

Manzhouli College of Inner Mongolia University

yong wang

Inner Mongolia Academy of Agricultural and Animal Husbandry Sciences

Xingfu Yun

Inner Mongolia Agricultural University

\section{Research Article}

Keywords: Phytophthora infestans, attenuated strain, growth and pathogenicity, RNA-seq, bioinformatics analysis, DEGs

Posted Date: April 20th, 2021

DOI: https://doi.org/10.21203/rs.3.rs-425506/v1

License: (영 This work is licensed under a Creative Commons Attribution 4.0 International License. Read Full License

Version of Record: A version of this preprint was published at International Microbiology on July 13th, 2021. See the published version at https://doi.org/10.1007/s10123-021-00195-9. 


\section{Abstract}

Phytophthora infestans is a hemibiotroph oomycete that primarily infects tomato. In this study, the growth status and pathogenicity of attenuated and virulent strains of Phytophthora infestans were determined. Furthermore, RNA-seq technology was used to explore the differences in gene transcription levels between attenuated and virulent strains. Gene Ontology (GO) classification and Kyoto Encyclopedia of Genes and Genomes (KEGG) pathway enrichment analyses were performed on the differentially expressed genes (DEGs) obtained by sequencing, and the significant DEGs related to the growth and pathogenicity of the strains were screened from the significantly enriched pathways. The results revealed that compared with the virulent strain, the growth of the attenuated strain was inhibited, the structure of hyphae was destroyed, and the disease index was decreased. The differences in the growth status and disease index of the attenuated strain were related to changes in several metabolic pathways, and the DEGs in the metabolic pathways indicated alterations in the attenuated strain growth and pathogenicity. There were 2,651 DEGs in the attenuated strain, of which 1,086 were up-regulated and 1,565 were down-regulated. The inhibited growth of the attenuated strain was associated with accumulation of excessive glucose, decomposition of serine/glycine, and reduction of tryptophan synthesis. The reduced pathogenicity of the strain was associated with degradation of the cell wall and reduced formation of melanin and a-keto butyric acid. These results could offer insights into the mechanisms of attenuation of Phytophthora infestans.

\section{Introduction}

Tomato late blight is an important plant disease that seriously threatens the cultivation and production of tomatoes. In recent years, with the changes in planting methods and the popularization and application of large-scale greenhouses, outbreaks of late blight have become more serious and more frequent (Zhao et al. 2020). Tomato late blight is caused by the infestation of Phytophthora infestans (Mont.) De Bary (Mo et al. 2016; Hu et al. 2018; Liu et al. 2019; Zhi et al. 2020). Tomato leaves, stems, flowers, and fruits can be infected, endangering the entire growth period of the tomato. In severe cases, the stems may rot, the plants can wilt, and the fruits may turn brown (Liu et al. 2020). Phytophthora is presently assigned to class Oomycetes. The hyphae are colorless and thin, without a septum (Yin et al. 2016). The pathogen grows in the interstitial spaces of the host cells, and several filamentous structures are used to penetrate the host cells to absorb nutrients. The white mold on the diseased spots is composed of the septal stalk and sporangium of the pathogen. The host range is relatively narrow, and among cultivated plants, only tomatoes and potatoes are infected (Wa 2019). Although Phytophthora infestans can overwinter by means of oospores, it mainly overwinters as hyphae or sporangia. The spores are spread by air currents, and they infect host plants when the temperature and humidity are suitable (Li 2020). The conditions for infecting tomatoes are low temperature and high humidity, and the symptoms of late blight may also appear in tropical areas under suitable weather conditions in winter (Tewodros et al. 2019).

In 1965, the French phytologist Grente investigated a susceptible chestnut forest in Italy and found that the pathogens isolated from typical and atypical ulcers were different. Grente called this white strain an attenuated strain of chestnut blight, because the attenuated strain had a cross-protective effect on the 
virulent strain. This finding opened new directions for the control of chestnut blight (Du and Zhang 2000). Since then, related ideas such as the use of attenuated, low-virulence, or non-pathogenic strains have been examined (Qian et al. 2013). Qian (2013) screened out an attenuated strain of Fusarium oxysporum f. sp. cucumerinum by using fresh root extract of celery and constructed an induction system demonstrating that the attenuated strain could effectively control the blight. Wang et al. (2014) isolated a strain of Botryosphaeria dothidea with abnormal colony morphology, strain LW-1, that showed weak pathogenicity and low virulence when infecting hosts. Ding et al. (2017) isolated the Bd CV1-G1 strain from Botryosphaeria dothidea, a strain that affected the growth of the host but demonstrated weakened pathogenicity. Zhao (2018) screened an attenuated Verticillium dahliae strain Vn-1 that met the evaluation criteria of attenuated strains, and its disease index was 9.43 .

Transcriptome refers to the collection of all transcription products in cells, tissues, or organisms under specific physiological conditions. Transcriptome provides a link between genomic genetic information and proteome with biological functions (Yao et al. 2017). Transcriptome sequencing technology has been widely used to study the pathogenic mechanism of fungi, such as Verticillium dahliae, Puccinia triticinia, Curvularia lunata, and Magnaporthe oryzae (Duressa et al. 2013; Zhang 2014; Gao et al. 2014; Choi et al. 2015).

In this study, we compared the virulent and attenuated strains of Phytophthora infestans, with the goals of obtaining comprehensive information on the morphology and transcriptome of the attenuated strain and using this information to analyze the relationships between the growth, pathogenicity, and metabolic pathways. This knowledge will help to clarify the mechanism of the attenuated strain.

\section{Materials And Methods}

\subsection{Strains and culture medium}

The virulent strain of Phytophthora infestans in this experiment was provided by the Institute of Plant Protection, Chinese Academy of Agricultural Sciences; the attenuated strain of Phytophthora infestans was screened and obtained by our research group. Potato dextrose agar (PDA, Becton, Dickinson and Co., MD, USA) medium was used to cultivate the strains.

\subsection{Determination of strain growth status and pathogenicity 2.2.1 Determination of strain growth status}

Under aseptic conditions, we used a hole punch with a diameter of $0.6 \mathrm{~cm}$ to sample attenuated and virulent strains of the fungus. An inoculation needle was used to transfer the fungus cake into $30 \mathrm{~mL}$ potato dextrose broth (PDB, Becton Dickinson) medium, and the sample was cultured at $25^{\circ} \mathrm{C}$ in the dark with shaking at $130 \mathrm{rpm}$. Samples were collected at $144 \mathrm{~h}$ after inoculation. Mycelia were first collected by filtration through a stainless steel sieve (40 mesh), washed with distilled water, and then lyophilized. The weight of dried mycelia was recorded as the biomass (g) (Hu et al. 2017). The fungus cakes were transferred to $20 \mathrm{~mL}$ PDA medium with the hyphae face down; one piece was taken from each petri dish 
and placed in the center of the PDA medium, cultured in a constant temperature incubator at $25^{\circ} \mathrm{C}$ for 144 $\mathrm{h}$. The changes of the attenuated strain was examined under an optical epifluorescence microscope (BX53 Olympus, Tokyo, Japan) at 200-fold magnification and compared with the structures of the virulent strain. The mycelium of Phytophthora infestans on the growth PDA medium was directly photographed by using a digital camera. Colony diameter $(\mathrm{cm})$ was measured as described by Pekşen et al. (2013). Each experimental group contained five biological replicates.

\subsubsection{Determination of strain pathogenicity}

After $144 \mathrm{~h}$ of culture, the fungus cakes of attenuated and virulent strains were washed with sterile water to prepare suspensions. Under the microscope, the spore concentration was adjusted to $5.0 \times 10^{4}$ sporangia $/ \mathrm{mL}$, and the prepared suspension was placed in a normal temperature box for $2-3 \mathrm{~h}$. The strains were tested at the 6-8 leaf stages of tomato seedlings. The suspension was sprayed evenly on the front and back sides of the leaves using a sprayer. The front and back sides of leaves were covered with uniform fungal suspension as the standard. The inoculation treatment was carried out at 6-7 p.m., and leaves were kept warm and moist in a small shed after spraying. From the first appearance of symptoms, the diseased plant rate and diseased leaf rate of tomato plants in each group were recorded according to the disease grade standards (Chai et al. 2005). The disease index was calculated once every 3 days, with 24 plants in each experimental group and 3 biological replicates per treatment.

The grading standards were as follows: Grade 0 : asymptomatic; Grade $1: \leq 5 \%$ of the leaf area was infected to form small necrotic spots; Grade 2: $6-15 \%$ of the leaf area was infected to form restrictive necrotic spots; Grade 3: 16-30\% of the leaf area was infested, and no necrotic spot was formed on the stem; Grade 4: 31-60\% of the leaf area was infected, or small necrotic spots were formed on the stem; Grade 5: $61-90 \%$ of the leaf area was infected, or the stem formed expanded spots; Grade $6: 91-100 \%$ of the leaf area was infected, or the stem was damaged, or the plants died.

The disease index $(\%)=\sum$ (number of diseased leaves at each level $\times$ corresponding grade value) / (total number of investigated leaves $\times$ highest grade value) $\times 100 \%$ ( Zhu et al. 2020).

\subsection{RNA sample preparation}

After $144 \mathrm{~h}$ of inoculation, sterile tweezers were used to carefully scrape about $300 \mathrm{mg}$ of the cultured mycelium from each fungus cake, and the samples were placed in pre-marked cryopreservation tubes (the cryopreservation tube number $\mathrm{T}$ represents the attenuated strain; number $\mathrm{C}$ represents the virulent strain), frozen in liquid nitrogen, and stored in an ultra-low temperature refrigerator at $-80^{\circ} \mathrm{C}$ for later use. Each experimental group contained three biological replicates.

\subsection{RNA library construction}

Total RNA was extracted from mycelium samples by a mirVana miRNA Isolation Kit (Ambion, Texas, USA) following the manufacturer's instructions. RNA purity was checked by using a NanoDrop 2000, and the concentration was measured using a Qubit RNA Assay Kit (Life Technologies, CA, USA). RNA integrity was assessed using the RNA Nano 6000 Assay Kit of the Bioanalyzer 2100 system (Agilent Technologies, 
Santa Clara, CA, USA). A total of $4 \mu \mathrm{g}$ RNA per sample was used as input material for the RNA sample preparation. The libraries were constructed using a TruSeq Stranded mRNA LTSample Prep Kit (Illumina, San Diego, CA, USA) according to the manufacturer's instructions. The libraries were sequenced on an Illumina sequencing platform (HiSeq ${ }^{\text {TM }} 2500$ ) by OE biotech Co., Ltd. (Shanghai, China).

\subsection{Bioinformatics analysis}

Raw reads were processed using Trimmomatic (Bolger et al. 2014). The reads containing adapters, ploy-N, and low quality sequences were removed to obtain the clean reads. Clean read data were examined for Q30 and GC content to ensure high quality. After removing low-quality sequences, the clean reads were assembled into expressed sequence tag clusters (contigs) and de novo assembled into transcripts by using Trinity version 2.4 (Grabherr et al. 2011) in paired-end mode. The longest transcript was chosen as a unigene based the similarity and length of the sequence for subsequent analysis. The functions of the unigenes were annotated by alignment with the NCBI nonredundant (NR), SwissProt, and Clusters of orthologous groups for eukaryotic complete genomes (KOG) databases using blastx (Altschul et al. 1990) with a threshold E-value of $10^{-5}$, and the FPKM values (Trapnell et al. 2010) of each unigene was calculated using eXpress (Roberts et al. 2013). DEGs were identified using the DESeq (Simon and Wolfgang 2013) functions estimateSizeFactors and nbinomTest. $P$ value $<0.05$ and $\| \log _{2}$ fold changel $>1$ were set as the threshold criteria for differential expression. GO and KEGG (Kanehisa et al. 2008) enrichment analysis of DEGs was performed to determine the biological functions or pathways involving these genes.

\subsection{Significant DEGs analysis of related KEGG pathways}

According to the reported genes, proteins, and enzymes related to the growth and pathogenicity of strains, the related significant DEGs were screened from the significantly enriched pathways between the attenuated and virulent strains. $Q$ value (FDR-adjusted $P$ value) $<0.05$ and $\mid \log _{2}$ fold changel $>1$ were set as the threshold criteria for significantly differential expression.

\section{Results}

\subsection{Growth status and pathogenicity of strains}

\subsubsection{Growth status of strains}

After $144 \mathrm{~h}$ of constant temperature culture at $25^{\circ} \mathrm{C}$, the strains were photographed, observed under microscope, and growth indexes were measured (Figs. 1). Microscopic observation showed that the fungal mycelia presented differential changes. The mean colony diameters of the attenuated and virulent strains were $3.418 \mathrm{~cm}$ and $7.508 \mathrm{~cm}$, and the mean mycelia biomasses were $0.224 \mathrm{~g}$ and $0.347 \mathrm{~g}$, respectively. The morphological characteristics of attenuated and virulent strains were also quite different (Table 1). By observing the growth status of mycelia, the viability and integrity of the samples were ensured. 
Table 1

Morphological characteristics of different strains

\begin{tabular}{|c|c|c|c|c|}
\hline $\begin{array}{l}\text { Sample } \\
\text { name }\end{array}$ & $\begin{array}{l}\text { Colony } \\
\text { color }\end{array}$ & Colony morphology & Aerial hypha & $\begin{array}{l}\text { Growth } \\
\text { rate }\end{array}$ \\
\hline $\begin{array}{l}\text { Attenuated } \\
\text { strain }\end{array}$ & $\begin{array}{l}\text { The front is } \\
\text { white, } \\
\text { the back is } \\
\text { light pink }\end{array}$ & $\begin{array}{l}\text { Nearly round, flat, and } \\
\text { edge regular }\end{array}$ & $\begin{array}{l}\text { Short, compact, fluffy, } \\
\text { and white }\end{array}$ & Slow \\
\hline $\begin{array}{l}\text { Virulent } \\
\text { strain }\end{array}$ & $\begin{array}{l}\text { The front is } \\
\text { light pink, } \\
\text { the back is } \\
\text { dark pink }\end{array}$ & $\begin{array}{l}\text { Round, obvious raised in the } \\
\text { middle, and edge strigose }\end{array}$ & $\begin{array}{l}\text { Long, loose, flocculent, } \\
\text { grow upward, and white }\end{array}$ & Quick \\
\hline
\end{tabular}

\subsubsection{Determination of strains pathogenicity}

Tomato seedlings were inoculated with the suspensions of attenuated and virulent strains at the 6-8 leaf stages. From the first appearance of symptoms, the disease indexes of different strains were calculated (Table 2) to observe the changes in pathogenicity.

Table 2

Disease indexes of tomato seedlings inoculated with different strains (\%)

\begin{tabular}{|lllllllll|}
\hline Days after inoculation & $\mathbf{3 d}$ & $\mathbf{6 d}$ & $\mathbf{9 d}$ & $\mathbf{1 2 d}$ & $\mathbf{1 5 d}$ & $\mathbf{1 8 d}$ & $\mathbf{2 1 d}$ \\
\hline Attenuated strain & 0.17 & 0.26 & 0.61 & 1.31 & 3.32 & 3.84 & 4.45 \\
\hline Virulent strain & 1.41 & 5.2 & 7.14 & 8.91 & 12.79 & 16.05 & 19.66 \\
\hline $\mathbf{3 . 2}$ Quality analysis of total RNA & & & &
\end{tabular}

Total RNA quality results were obtained after RNA-Seq sequencing of six samples (Table 3). Trinity (Grabherr et al. 2011) software was used to splice and assemble the clean reads data obtained by sequencing, and the transcripts obtained were further spliced to obtain Unigene results (Table 4). Subsequent data analysis was performed according to the quality statistics of the sequencing data. 
Table 3

Quality results of total RNA

\begin{tabular}{|c|c|c|c|c|c|c|}
\hline Sample & Raw Reads & Clean Reads & Total mapped reads & $\begin{array}{l}\text { Uniquely } \\
\text { mapped }\end{array}$ & Q30\% & GC\% \\
\hline T1 & $48.01 \mathrm{M}$ & $47.50 \mathrm{M}$ & $\begin{array}{l}44.34 \mathrm{M} \\
(93.34 \%)\end{array}$ & $\begin{array}{l}43.73 \mathrm{M} \\
(92.06 \%)\end{array}$ & 95.56 & 53.01 \\
\hline T2 & $45.73 \mathrm{M}$ & $45.27 \mathrm{M}$ & $\begin{array}{l}42.18 \mathrm{M} \\
(93.18 \%)\end{array}$ & $\begin{array}{l}41.62 \mathrm{M} \\
(91.93 \%)\end{array}$ & 95.60 & 52.98 \\
\hline T3 & $45.60 \mathrm{M}$ & $45.35 \mathrm{M}$ & $\begin{array}{l}42.25 \mathrm{M} \\
(93.17 \%)\end{array}$ & $\begin{array}{l}41.71 \mathrm{M} \\
(91.95 \%)\end{array}$ & 97.16 & 52.94 \\
\hline $\mathrm{C} 1$ & $47.14 \mathrm{M}$ & $46.56 \mathrm{M}$ & $\begin{array}{l}42.95 \mathrm{M} \\
(92.25 \%)\end{array}$ & $\begin{array}{l}42.34 \mathrm{M} \\
(90.93 \%)\end{array}$ & 96.40 & 52.68 \\
\hline C2 & $46.30 \mathrm{M}$ & $45.73 \mathrm{M}$ & $\begin{array}{l}42.52 \mathrm{M} \\
(92.99 \%)\end{array}$ & $\begin{array}{l}41.91 \mathrm{M} \\
(91.65 \%)\end{array}$ & 96.56 & 52.47 \\
\hline C3 & $47.51 \mathrm{M}$ & $47.20 \mathrm{M}$ & $\begin{array}{l}43.81 \mathrm{M} \\
(92.82 \%)\end{array}$ & $\begin{array}{l}43.17 \mathrm{M} \\
(91.47 \%)\end{array}$ & 97.04 & 52.65 \\
\hline
\end{tabular}

Table 4

Statistics of splicing results

\begin{tabular}{|lllllllll|}
\hline Term & All & >=500bp & >=1000bp & N50 & $\begin{array}{l}\text { Total } \\
\text { Length }\end{array}$ & $\begin{array}{l}\text { Max } \\
\text { Length }\end{array}$ & $\begin{array}{l}\text { Min } \\
\text { Length }\end{array}$ & $\begin{array}{l}\text { Average } \\
\text { Length }\end{array}$ \\
\hline Unigene & 19,843 & 15,324 & 10,744 & 2,079 & $28,794,426$ & 23,524 & 302 & $1,451.11$ \\
\hline
\end{tabular}

\subsection{Screening of DEGs}

To analyze the differential expression of the attenuated strain (Treat) and the virulent strain (Control), RNA reads were mapped to the genome. Principal component analysis (PCA) indicated that Treat and Control formed separated clusters, indicating distinct transcriptional profiles (Fig. 2a). The attenuated strain was more variable than the virulent strain. A volcano plot was drawn for the differential transcriptional profile results of Treat and Control (Fig. 2b). The attenuated strain had 2,651 DEGs $\left(P<0.05, \| \log _{2}\right.$ fold changel $>$ 1) compared to the virulent strain, of which 1,086 DEGs were up-regulated and 1,565 DEGs were downregulated. Up-regulated genes may positively regulate the pathogenic process, while down-regulated genes have an impact on the pathogenicity of fungal pathogens from the aspect of negative regulation.

\subsection{G0 enrichment analysis}


A GO classification enrichment analysis was performed on the DEGs between the attenuated and virulent strains (Fig. 3). GO terms having a corrected value of $P<0.05$ were considered to be statistically significant. In the GO database, DEGs are classified into three categories according to their function: biological process, cellular component, and molecular function. There are 23 sub-functional categories within biological processes, among which biological regulation, cellular process, establishment of localization, localization, metabolic process, and response to stimulus were the six categories with the most DEGs; cellular component has 20 sub-functional categories, among which cell, cell part, membrane, membrane part, and organelle were the five categories with the most DEGs. Molecular function has 21 subfunctional categories, among which binding, catalytic activity, and transporter activity were the three categories with the most DEGs. It was worth noting that the DEGs in protein tag were all down-regulated, while the DEGs in rhythmic process, electron carrier activity, and protein binding transcription factor activity were all up-regulated in the 64 sub-functional categories. These genes may be involved in the growth and pathogenicity of the fungi.

\subsection{KEGG enrichment analysis}

A KEGG pathway enrichment analysis was performed on the DEGs between the attenuated and virulent strains, and the top 20 metabolic pathways with the most significant enrichment were selected and used to construct a KEGG enrichment scatter plot (Fig. 4). The results showed that the DEGs were mainly concentrated in starch and sucrose metabolism (ko00500), tyrosine metabolism (ko00350), glycine/serine and threonine metabolism (ko00260), isoquinoline alkaloid biosynthesis (ko00950), and fatty acid degradation (ko00071) pathways. Among the significantly enriched pathways, metabolic and biosynthetic pathways were the most numerous, with 20 pathways accounting for $87 \%$ of the total. The results suggest that the key DEGs of these pathways were closely related to the growth and pathogenicity of the fungi.

\subsection{Genes involved in growth of strains}

In this study, twenty-seven significant DEGs related to growth were screened (Table 5). Twenty genes were up-regulated, and seven genes were down-regulated. Among these genes, $E G$ (endoglucanase), $C B H C$ (cellulose 1,4-beta-cellobiosidase), CelB (cellulase), $g l g C$ (glucose-1-phosphate adenyl transferase), $b g / X$ (beta-glucosidase), malZ (alpha-glucosidase), SGA (glucoamylase), amyA (alpha-amylase) and IMA (oligo1,6-glucosidase) encode enzymes involved in glucose production; $g l y A$ (serine hydroxy methyltransferase), GLDC (glycine dehydrogenase), AMT (amino methyl transferase) and PIPOX (sarcosine oxidase) encode enzymes involved in the decomposition of serine and glycine; $\operatorname{Trp} B$ (tryptophan synthase beta chain) encodes an enzyme involved in the synthesis of tryptophan. $E G, C B H C$, and $C e l B$ had the most significantly up-regulated expression levels at 44.782, 38.196, and 31.847 times the control group (virulent strain), respectively. 
Table 5

Significant DEGs related to the growth of strains

\begin{tabular}{|c|c|c|c|c|c|c|}
\hline Pathway & $\begin{array}{l}\text { Gene } \\
\text { name }\end{array}$ & Gene ID & $\begin{array}{l}\text { Fold } \\
\text { change }\end{array}$ & Type & $\mathrm{Q}$ value & Enzyme family \\
\hline ko00950 & \multirow[t]{2}{*}{$\operatorname{tyn} A$} & \multirow[t]{2}{*}{ TRINITY_DN2405_c0_g2_i1 } & \multirow[t]{2}{*}{26.020} & \multirow[t]{2}{*}{ Up } & \multirow{2}{*}{$\begin{array}{l}1.59 \mathrm{E}- \\
05\end{array}$} & \multirow{2}{*}{$\begin{array}{l}\text { primary-amine } \\
\text { oxidase }\end{array}$} \\
\hline ko00350 & & & & & & \\
\hline \multirow[t]{2}{*}{ ko00260 } & & TRINITY_DN6172_c0_g1_i1 & 2.492 & Up & $\begin{array}{l}8.25 \mathrm{E}- \\
05\end{array}$ & \\
\hline & & TRINITY_DN9895_c0_g1_i1 & 2.435 & Up & 0.00085 & \\
\hline \multirow[t]{12}{*}{ ko00500 } & $E G$ & TRINITY_DN2685_c0_g1_i1 & 44.782 & Up & 0.0059 & endoglucanase \\
\hline & $\mathrm{CBHC}$ & TRINITY_DN483_c0_g1_i1 & 38.196 & Up & 0.028 & $\begin{array}{l}\text { cellulose 1,4- } \\
\text { beta- } \\
\text { cellobiosidase }\end{array}$ \\
\hline & CelB & TRINITY_DN12353_c0_g1_i1 & 31.847 & Up & $\begin{array}{l}9.05 \mathrm{E}- \\
25\end{array}$ & cellulase \\
\hline & $g \lg C$ & TRINITY_DN910_c0_g1_i1 & 15.699 & Up & 0.0040 & $\begin{array}{l}\text { glucose-1- } \\
\text { phosphate } \\
\text { adenyl } \\
\text { transferase }\end{array}$ \\
\hline & $b g I X$ & TRINITY_DN16729_c0_g1_i1 & 5.725 & Up & $\begin{array}{l}7.80 \mathrm{E}- \\
08\end{array}$ & beta-glucosidase \\
\hline & & TRINITY_DN4010_c0_g1_i1 & 5.373 & Up & $\begin{array}{l}1.80 \mathrm{E}- \\
05\end{array}$ & \\
\hline & & TRINITY_DN3408_c0_g2_i1 & 3.701 & Up & $\begin{array}{l}7.03 \mathrm{E}- \\
09\end{array}$ & \\
\hline & & TRINITY_DN9742_c0_g1_i1 & 2.289 & Up & 0.021 & \\
\hline & malZ & TRINITY_DN9963_c0_g1_i1 & 4.462 & Up & 0.00043 & $\begin{array}{l}\text { alpha- } \\
\text { glucosidase }\end{array}$ \\
\hline & $S G A 1$ & TRINITY_DN3369_c0_g1_i1 & 4.136 & Up & $\begin{array}{l}2.44 \mathrm{E}- \\
12\end{array}$ & glucoamylase \\
\hline & amyA & TRINITY_DN15061_c0_g1_i1 & 3.404 & Up & 0.0013 & alpha-amylase \\
\hline & IMA & TRINITY_DN707_c0_g1_i1 & 2.278 & Up & 0.00052 & $\begin{array}{l}\text { oligo-1,6- } \\
\text { glucosidase }\end{array}$ \\
\hline \multirow[t]{2}{*}{ ko00260 } & glyA & TRINITY_DN14981_c0_g1_i1 & 2.779 & Up & $\begin{array}{l}2.62 \mathrm{E}- \\
07\end{array}$ & $\begin{array}{l}\text { serine } \\
\text { hydroxymethyl } \\
\text { transferase }\end{array}$ \\
\hline & $G L D C$ & TRINITY_DN16738_c0_g1_i1 & 2.535 & Up & $\begin{array}{l}7.80 \mathrm{E}- \\
07\end{array}$ & $\begin{array}{l}\text { glycine } \\
\text { dehydrogenase }\end{array}$ \\
\hline
\end{tabular}




\begin{tabular}{|c|c|c|c|c|c|c|}
\hline Pathway & $\begin{array}{l}\text { Gene } \\
\text { name }\end{array}$ & Gene ID & $\begin{array}{l}\text { Fold } \\
\text { change }\end{array}$ & Type & $\mathrm{Q}$ value & Enzyme family \\
\hline & $A M T$ & TRINITY_DN1768_c0_g1_i1 & 2.278 & Up & $\begin{array}{l}2.17 \mathrm{E}- \\
05\end{array}$ & $\begin{array}{l}\text { amino methyl } \\
\text { transferase }\end{array}$ \\
\hline & PIPOX & TRINITY_DN12573_c0_g1_i1 & 2.079 & Up & 0.017 & $\begin{array}{l}\text { sarcosine } \\
\text { oxidase }\end{array}$ \\
\hline ko00071 & ato $B$ & TRINITY_DN1530_c0_g2_i1 & 12.296 & Up & 0.024 & $\begin{array}{l}\text { acetyl-CoA C- } \\
\text { acetyltransferase }\end{array}$ \\
\hline & $T Y R$ & TRINITY_DN16117_c0_g1_i1 & 0.457 & Down & $\begin{array}{l}5.49 \mathrm{E}- \\
05\end{array}$ & tyrosinase \\
\hline \multicolumn{7}{|l|}{ ko00350 } \\
\hline & & TRINITY_DN12772_c0_g1_i1 & 0.342 & Down & 0.0073 & \\
\hline & & TRINITY_DN17109_c0_g1_i1 & 0.244 & Down & $\begin{array}{l}2.68 \mathrm{E}- \\
07\end{array}$ & \\
\hline & & TRINITY_DN2405_c0_g1_i1 & 0.082 & Down & $\begin{array}{l}4.07 \mathrm{E}- \\
07\end{array}$ & \\
\hline ko00350 & $g a b D$ & TRINITY_DN8611_c0_g1_i1 & 0.491 & Down & 0.0019 & $\begin{array}{l}\text { succinate- } \\
\text { semialdehyde } \\
\text { dehydrogenase }\end{array}$ \\
\hline \multirow[t]{2}{*}{ ko00260 } & $i / v A$ & TRINITY_DN8283_c0_g1_i1 & 0.461 & Down & 0.0028 & $\begin{array}{l}\text { threonine } \\
\text { dehydratase }\end{array}$ \\
\hline & $\operatorname{trp} B$ & TRINITY_DN13540_c0_g1_i1 & 0.190 & Down & 0.0017 & $\begin{array}{l}\text { tryptophan } \\
\text { synthase beta } \\
\text { chain }\end{array}$ \\
\hline
\end{tabular}

\subsection{Genes involved in pathogenicity of strains}

In this study, nine significant DEGs related to pathogenicity were screened (Table 6). Four genes were upregulated, and five genes were down-regulated, including $b g I X$ (beta-glucosidase) encode enzymes involved in cell wall degradation, TYR (tyrosinase) encode enzymes involved in melanin formation, and ilvA (threonine dehydratase) encodes an enzyme involved in a-ketobutyric acid formation. TYR had the most significantly down-regulated expression level, 0.082 times that of the control group (virulent strain). 
Table 6

Significant DEGs related to the pathogenicity of strains

\begin{tabular}{|c|c|c|c|c|c|c|}
\hline Pathway & $\begin{array}{l}\text { Gene } \\
\text { name }\end{array}$ & Gene ID & $\begin{array}{l}\text { Fold } \\
\text { change }\end{array}$ & Type & $\begin{array}{l}Q \\
\text { value }\end{array}$ & $\begin{array}{l}\text { Enzyme } \\
\text { family }\end{array}$ \\
\hline \multirow[t]{4}{*}{ ko00500 } & $b g / X$ & TRINITY_DN16729_c0_g1_i1 & 5.725 & Up & $\begin{array}{l}7.80 \mathrm{E}- \\
08\end{array}$ & $\begin{array}{l}\text { beta- } \\
\text { glucosidase }\end{array}$ \\
\hline & & TRINITY_DN4010_c0_g1_i1 & 5.373 & Up & $\begin{array}{l}1.80 \mathrm{E}- \\
05\end{array}$ & \\
\hline & & TRINITY_DN3408_c0_g2_i1 & 3.701 & Up & $\begin{array}{l}7.03 E- \\
09\end{array}$ & \\
\hline & & TRINITY_DN9742_c0_g1_i1 & 2.289 & Up & 0.021 & \\
\hline \multirow{5}{*}{$\begin{array}{l}\text { ko00950 } \\
\text { ko00350 }\end{array}$} & $T Y R$ & TRINITY_DN16117_c0_g1_i1 & 0.457 & Down & $5.49 \mathrm{E}-$ & tyrosinase \\
\hline & & & & & & \\
\hline & & TRINITY_DN12772_c0_g1_i1 & 0.342 & Down & 0.0073 & \\
\hline & & TRINITY_DN17109_c0_g1_i1 & 0.244 & Down & $\begin{array}{l}2.68 \mathrm{E}- \\
07\end{array}$ & \\
\hline & & TRINITY_DN2405_c0_g1_i1 & 0.082 & Down & $\begin{array}{l}4.07 \mathrm{E}- \\
07\end{array}$ & \\
\hline ko00260 & $i / v A$ & TRINITY_DN8283_c0_g1_i1 & 0.461 & Down & 0.0028 & $\begin{array}{l}\text { threonine } \\
\text { dehydratase }\end{array}$ \\
\hline
\end{tabular}

\section{Discussion}

Yan et al. (2016) showed that YePSA medium supplemented with a high concentration of glucose could inhibit the sexual reproduction and mycelial growth of Sporisorium scitamineum. Liang et al. (2014) showed that glucose could inhibit the mating ability of Candida albicans. By comparing the significant DEGs between attenuated and virulent strains, we found that the expression levels of twelve coding genes involved in glucose production were all up-regulated. This suggests that the attenuated strain might feature inhibition of mycelial growth and sexual reproduction through excessive glucose accumulation.

As a non-essential amino acid, L-serine participates in many biological metabolic processes, especially in cell proliferation and growth (Yang 2016). Glycine is an important raw material for nucleic acid synthesis. Lack of glycine can lead to the obstruction of DNA synthesis and the impairment of cell growth and proliferation (Wei and Yu 2018). The addition of folic acid showed that a high concentration of folic acid was detrimental to the growth of Corynebacterium glutamicum (Ren 2009). Comparison of the significant DEGs between attenuated and virulent strains showed that the expression levels of four coding genes involved in serine and glycine decomposition were up-regulated. This suggests that the attenuated strain might show inhibition of the mycelial growth rate through decomposition of serine/glycine and production of folic acid precursors. 
Studies have shown that low-activity tyrosinase $(T Y R)$ can reduce the browning degree of the SCAU1 strain (Yu 2018). Zhou (2019) found that the mutant strain of Candida albicans could not grow without the ilv2 gene. Studies have shown that tryptophan auxotrophic strains of Mycobacterium tuberculosis cannot survive and reproduce in macrophages (Bange et al. 1996; Gordhan et al. 2002). By comparing the significant DEGs between attenuated and virulent strains, seven down-regulated genes related to the growth of the strain were identified. This suggests that the colony color, colony diameter, and mycelial biomass of the attenuated strain might be affected through down-regulation of the expression of several related genes.

Beta-glucosidase ( $b g / X)$ participates in the metabolism of fungal cell walls; Phanerochaete chrysosporium can produce multiple $\beta-1,3$-glucosidases to jointly degrade cell walls (Chang 2017). The cell walls of fungi are involved in the formation of biofilms. For pathogenic fungi, the cell wall is important in virulence and pathogenicity, because fungal cell walls protect the strain from the host defense mechanisms (Li 2015). Tyrosinases in tyrosine metabolism are key enzymes involved in melanin synthesis (Yang 2019). Melanin is closely related to pathogenicity, and mutant strains that lack melanin production lose the pathogenicity due to lack of sufficient turgor (Zhang 2014). Studies have found that virulence of strains lacking the ilvC gene is nearly absent; after the deletion of ilv2 and ilv6 in Magnaporthe oryzae, the infectivity of mutants Moilv2 and Moilv6 decreased significantly (Zhou 2019). In comparisons of the significant DEGs between attenuated and virulent strains, the expression levels of four coding genes involved in cell wall degradation were all up-regulated; five coding genes involved in melanin and a-ketobutyric acid formation were all down-regulated. This suggests that the attenuated strain might be affected by the expression of genes related to the cell wall and the virulence factors, thereby affecting the pathogenicity of the strain.

\section{Conclusion}

In this study, compared with the virulent strain, the morphology and growth of the attenuated strain was significantly inhibited, and the field disease index was decreased. RNA-seq results showed that the growth of the attenuated strain was inhibited by accumulation of excessive glucose, decomposition of serine/glycine, and reduction of the synthesis of tryptophan. The pathogenicity of the strain was then reduced by degrading the cell wall and decreasing the formation of melanin and a-keto butyric acid. Through the morphological and transcriptomic comparative analysis between attenuated and virulent strains of Phytophthora infestans, the reasons for the difference in growth and pathogenicity between the strains were further revealed, and the results thus provide a foundation for the elucidation of the mechanisms of attenuated strains.

\section{Declarations}

Ethics approval and consent to participate: Compliance with Ethical Standards.

Consent for publication: Not applicable.

Availability of data and materials: Please contact author for data requests. 
Competing interests: Jiafang Liu, Lei Li, Yong Wang, and Xingfu Yun declare that they have no conflict of interest.

Funding: This work was supported by grants from the Key Projects of Applied Technology Research and Development of Inner Mongolia Autonomous Region (Grant number 201702068) and Science and Technology Achievement Transformation Project of Inner Mongolia Autonomous Region (Grant number CGZH2018140). The author of these projects is Xingfu Yun. Funding provides assistance for in the design of the study and collection, analysis, and interpretation of data and in writing the manuscript.

Authors' contributions: Xingfu Yun proposed research ideas and experimental design; Jiafang Liu conducted experimental research and data analysis, and was responsible for writing the first draft of the manuscript; Lei Li and Yong Wang participated in the revision and correction of the manuscript.

Acknowledgments: The authors are grateful to prof. Xiaojing Yan from Chinese Academy of Agricultural Sciences (Beijing, China) for her kindly providing virulent strain of Phytophthora infestans. We thank LetPub (www.letpub.com) for its linguistic assistance during the preparation of this manuscript.

\section{References}

1. Altschul SF, Gish W, Miller W, Myers EW, Lipman DJ (1990) Basic local alignment search tool. J Mol Biol 215:403-410. https://doi.org/10.1006/jmbi.1990.9999

2. Bange FC, Brown AM, Jacobs WR (1996) Leucine auxotrophy restricts growth of Mycobacterium bovis BCG in macrophages. Infect Immun 64:1794-1799. https://doi.org/10.1128/IAI.64.5.1794-1799.1996

3. Bolger AM, Lohse M, Usadel B (2014) Trimmomatic: a flexible trimmer for Illumina sequence data. Bioinformatics 30:2114. https://doi.org/10.1093/bioinformatics/btu170

4. Chai M, Yu SC, Jiang LG (2005) Pathogenicity of a new isolate of Phytophthora infestans from Beijing and resistance evaluation of tomato materials. Journal of North China Agriculture 4:98-101

5. Chang Q (2017) Study of the puccinia striiformis $f$. $s p$. Tritici sugar absorption mechanism in infection of wheat. Dissertation, Northwest A\&F University

6. Choi J, Chung HJ, Lee GW, Koh SK, Chae SK, Lee YH (2015) Genome-wide analysis of hypoxiaresponsive genes in the rice blast fungus, Magnaporthe oryzae. PLoS One 10: e0134939. https://doi.org/10.1 371/journal.pone.0134939

7. Ding Z, Zhou T, Guo LY (2017) Characterization of a novel strain of Botryosphaeria dothidea chrysovirus 1 from the apple white rot pathogen Botryosphaeria dothidea. Arch Virol 162: 2097-2102. https://doi.org/ 10.1007 /s00705-017-3320-6

8. Du JL, Zhang JL (2000) The approach on the defensive function of hypovirulent strains to Cryphonectria parasitica. Journal of Hebei Agricultural University 23:82-85

9. Duressa D, Anchieta A, Chen DQ, Klimes A, Garcia-Pedrajas MD, Dobinson KF, Klosterman SJ (2013) RNA-Seq analyses of gene expression in the microsclerotia of Verticillium dahliae. BMC Genom 14:607. https://doi.org/10.1186/1471-2164-14-607 
10. Gao SG, Li YQ, Gao JX, Suo YJ, Fu KH, Li YY, Jie C (2014) Genome sequence and virulence variationrelated transcriptome profiles of Curvularia lunata, an important maize pathogenic fungus. BMC Genom 15:627. https://doi.org/10.1186/1471-2164-15-627

11. Gordhan BG, Smith DA, Alderton H, McAdam RA, Bancroft GJ, Mizrahi V (2002) Construction and phenotypic characterization of an auxotrophic mutant of Mycobacterium tuberculosis defective in Larginine biosynthesis. Infect Immun 70:3080-3084. https://doi.org/10.1128/IAI.70.6.3080-3084.2002

12. Grabherr MG, Haas BJ, Yassour M, Levin JZ, Amit I, Thompson DA, Adiconis X, Fan L, Raychowdhury R, Zeng QD, Chen ZH, Mauceli E, Hacohen N, Gnirke A, Rhind N, Palma FD, Birren BW, Nusbaum C, Lindblad-Toh K, Friedman N, Regev A (2013) Trinity: reconstructing a full-length transcriptome without a genome from RNA-Seq data. Nat Biotechnol 29:644-652. https://doi.org/10.1038/nbt.1883

13. Hu GS, Huang CG, Zhang Yang XW, Jia JM (2017) Accumulation of biomass and four triterpenoids in two-stage cultured Poria cocos mycelia and diuretic activity in rats. Chin J Nat Med 15:265-270. https://doi.org/10.1016/S1875-5364(17)30043-2

14. Hu MY, Bai WQ, Pan XX, Wu H, Ru XJ, Luo J, Yin XG, Pan GH, Lei KR (2018) Analysis of tomato late blight resistance marker based on the analogues of Ph-3 gene. Acta Phytopathology 48: 560-566. https://doi.org/ 10.13926/j.cnki.apps.000149

15. Kanehisa M, Araki M, Goto S, Hattori M, Hirakawa M, Itoh M, Katayama T, Kawashima S, Okuda S, Tokimatsu T, Yamanishi Y (2008) KEGG for linking genomes to life and the environment. Nucleic Acids Res 36:D480-D484. https://doi.org/10.1093/nar/gkm882

16. Li MJ (2015) Functional analysis of UDP glucose pyrophosphorylase and phosphoglucomutase in the carbon metabolism of Ganoderma Iucidum. Dissertation, Nanjing Agricultural University

17. Li MY (2020) Prevention and treatment of tomato late blight. Vegetables 4:69-72 + $86+85$

18. Liang SH, Cheng JH, Deng FS, Tsai PA, Lin CH (2014) A novel function for Hog1 stress-activated protein kinase in controlling white-opaque switching and mating in Candida albicans. Eukaryot Cell 13:1557-1566. https://doi.org/10.1128/EC.00235-14

19. Liu MJ, Huang QD, Long B, Wang XY, Ou QQ, Huang XQ (2019) Screening of cherry tomatoes with late blight resistance in Guangxi. Northern Horticulture 2:20-24. https://doi.org/10.11937/bfyy.20181951

20. Liu YS, Liu YL, Huang SQ, Niu TT, Yuan HZ, Yan XJ (2020) Influence of application volume on the efficacy of UAV low-volume-spray to control tomato late blight. Pesticide Science Management 41:4652

21. Mo YR, Zhang PX, Deng MH, Yang ZA, Zhu HS, Zhang H, Bao JY, Hu WY, Tang XQ, Ma ZF, Wen L, Zhao $K$ (2016) Research on the excavation and response patterns of genes resistant to late blight located in the No.9 chromosome of tomato. Journal of China Agricultural University 21:527-533. https://doi.org/10.11841/j.issn.1007-4333.2016.08.07

22. Peksen A, Kibar B, Yakupoglu G (2013) Favourable culture conditions for mycelial growth of Hydnum repandum, a medicinal mushroom. African Journal of Traditional, Complementary, and Alternative Medicines: AJTCAM 10. https://doi.org/10.4314/ajtcam.v10i6.4 
23. Qian C (2013) Study on the screening of attenuated strains for Fusarium oxysporum f.sp.cucumerinum and induced resistance on cucumber wilt after treated with parsley extracts. Dissertation, Inner Mongolia Agricultural University

24. Qian C, Gao XM, Bao YY, Li J, Yun XF (2013) Screening of attenuated strains for Fusarium oxysporum f.sp.cucumerinum after treated with parsley seed extracts. Chin J Ecol 32:82-90. https://doi.org/10.13292/j.1000-4890.2013.0048

25. Ren JH (2009) Effect of folate Pathway on accumulation of L-serine in Corynebacterium glutamicum SYPS-062. Dissertation, Jiangnan University

26. Roberts $A$, Pachter $L$ (2013) Streaming fragment assignment for real-time analysis of sequencing experiments. Nat Methods 10:71-73. https://doi.org/10.1038/NMETH.2251

27. Simon A, Wolfgang H (2013) Differential expression of RNA-Seq data at the gene level- the DESeq package. European Molecular Biology Laboratory

28. Tewodros M, Kibrom A, Habte T, Bayeh M, Mohammed Y, Erik A, Erland L, Erik A (2019) Phosphite protects against potato and tomato late blight in tropical climates and has varying toxicity depending on the Phytophthora infestans isolate. Crop Prot 121:139-146. https://doi.org/10.1016/j.cropro.2019.03.019.

29. Trapnell C, Williams BA, Pertea G, Mortazavi A, Kwan G, Van Baren MJ, Salzberg SL, Wold BJ, Pachter L (2010) Transcript assembly and quantification by RNA-Seq reveals unannotated transcripts and isoform switching during cell differentiation. Nature Biotechnology 28: 511-515. https://doi.org/10.1038/nbt.1621

30. Wa TH (2019) Occurrence and control measures of tomato late blight. Nongjia Staff 24: 58

31. Wang LP, Jiang JJ, Wang YF, Hong Ni, Zhang FP, Xu WX, Wang GP (2014) Hypovirulence of the phytopathogenic fungus Botryosphaeria dothidea: assocication with a coninfecting Chrysovirus andPartitivirus. Journal of Virology88: 7517-7527. https://doi.org/10.1128/JVI.00538-14

32. Wei Z, Yu W (2018) One-carbon metabolism and anti-folate chemotherapeutic drugs. Chinese Journal of Cell Biology 40: 1973-1982. https://doi.org/10.11844/cjcb.2018.12.9002

33. Yan MX, Dai WJ, Cai EP, Deng YZ, Chang CQ, Jiang Z, Zhang LH (2016) Transcriptome analysis of Sporisorium scitamineum reveals critical environmental signals for fungal sexual mating and filamentous growth. BMC Genomics 17: 1-11. https://doi.org/10.1186/s12864-016-2691-5

34. Yang M (2016) Vousden KH serine and one-carbon metabolism in cancer. Nature Reviews Cancer 16: 650-662. https://doi.org/10.1038/nrc.2016.81

35. Yang WJ (2019) Melanin synthesis mechanism of Bacillus thuringiensis BMB171. Dissertation, Huazhong Agricultural University

36. Yao N, Liu XM, Dong YY, Wang N, Meng LL, Li HY (2017) Advances in application and sequencing methods of transcriptome. Northern \& Horticulture 12: 192-198. https://doi.org/10.11937/bfyy.201712043

37. Yin XY, Zhang GS, Han ZZ, Li BJ, Xie XW (2016) Occurrence and prevention of tomato late blight in non-cultivated solar greenhouse. China Vegetables 5: 88-89 
38. Yu XM (2018) Comparative study on browning and related mechanisms of different strains of Tricholoma giganteum. Dissertation, South China Agricultural University

39. Zhang HS (2014) Transcriptome analysis of two different pathotypes of Puccinia triticinia with different virulence. Dissertation, Hebei Agricultural University

40. Zhao LG, Zhang Y, Zhang TM, Zhao J, Wang YL, Li M (2020) Harm and epidemiological characteristics of tomato late blight in China. Modern Horticulture 43: 106-108.

https://doi.org/10.14051/j.cnki.xdyy.2020.19. 047

41. Zhao YJ (2018) The Mechanism of Resistance to Verticillium Wilt on SunflowerInduced by Gibellulopsis nigrescens Vn-1. Dissertation, Inner Mongolia Agricultural University

42. Zhi XN, Shu JS, Sun XR, Bai JR, Cui YN, Huang ZJ, Wang XX, Liu L, Du YC, Yan ZF, Li JM (2020) Screening and analysis of wild solanum pimpinellifolium species resistant to late blight. China Vegetables 2: 20-29

43. Zhou HX (2019) Studies on function of ketol acid reductoisomerase gene (MrilvC) in Metarhizium robertsii. Dissertation, Anhui Agricultural University

44. Zhu XM, Han MB, Chen QY, He YT, Wang DL, Liu F, Li HK (2020) Screening test of potato late blight control agents in Xintai city. Modern Agricultural Science and Technology 11: $114+116$

\section{Figures}

(a)

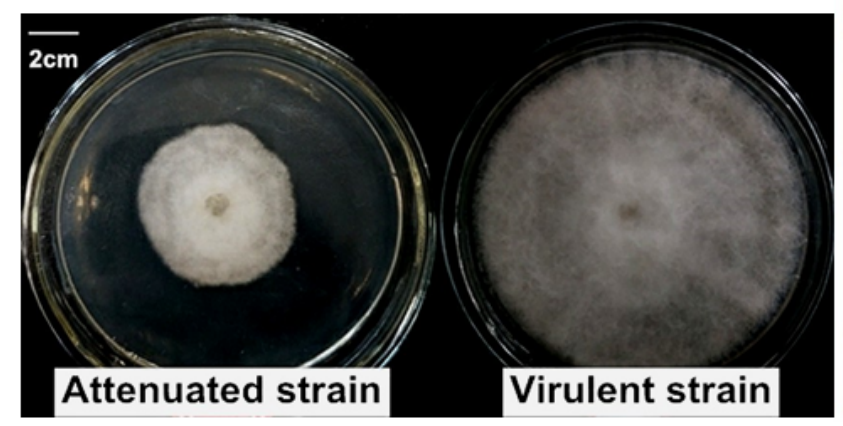

(c)

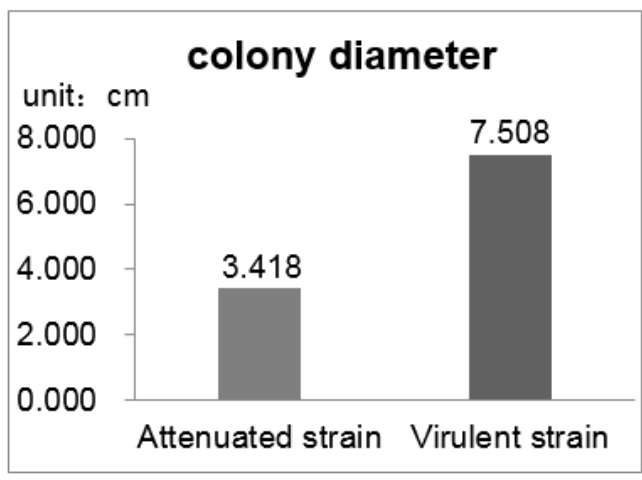

(b)
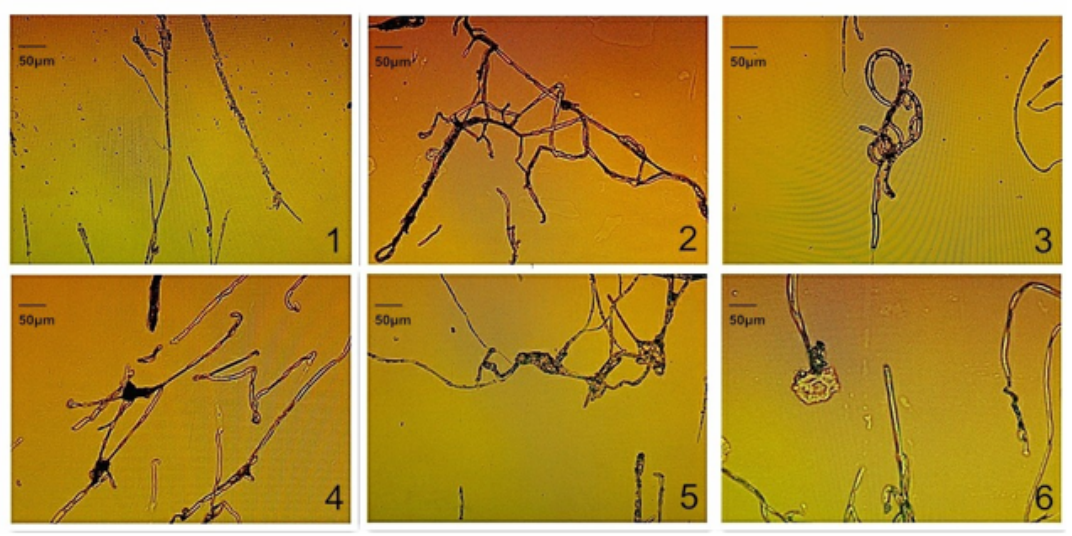

(d)

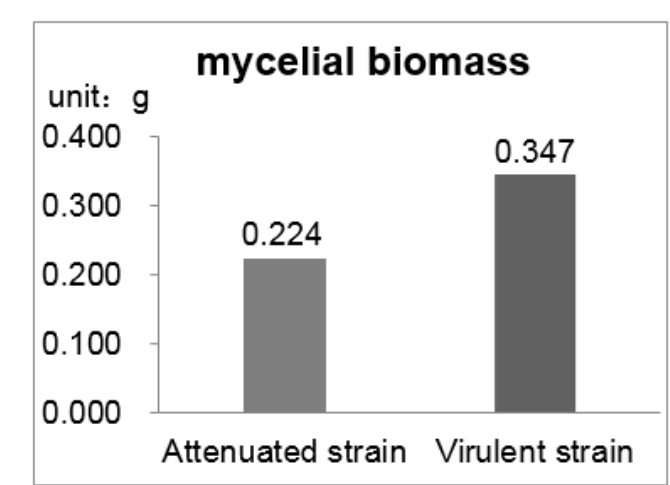


Figure 1

Comparison of growth status of strains Note: After the strains were cultured for 144 hours, photographs were taken, observed under microscope, and growth indexes were measured. The results were as follows: (a) Comparison of growth state of strains. (b) Comparison of microscopic changes of strains. (1) Normal mycelia of the virulent strain (CK); (2-6) mycelia of the attenuated strain. Hyphae wrapped around each other (2) and twisted (3); hyphae became bent, transparent, and local expansion (4); uneven distribution of hyphae thickness (5); protoplast leaked out (6). (c) Comparison of colony diameter. (d) Comparison of mycelia biomass. The $\mathrm{X}$-axis lists the sample names, and the $\mathrm{Y}$-axis is the growth index. The results in the figure are the average values of five replicates.
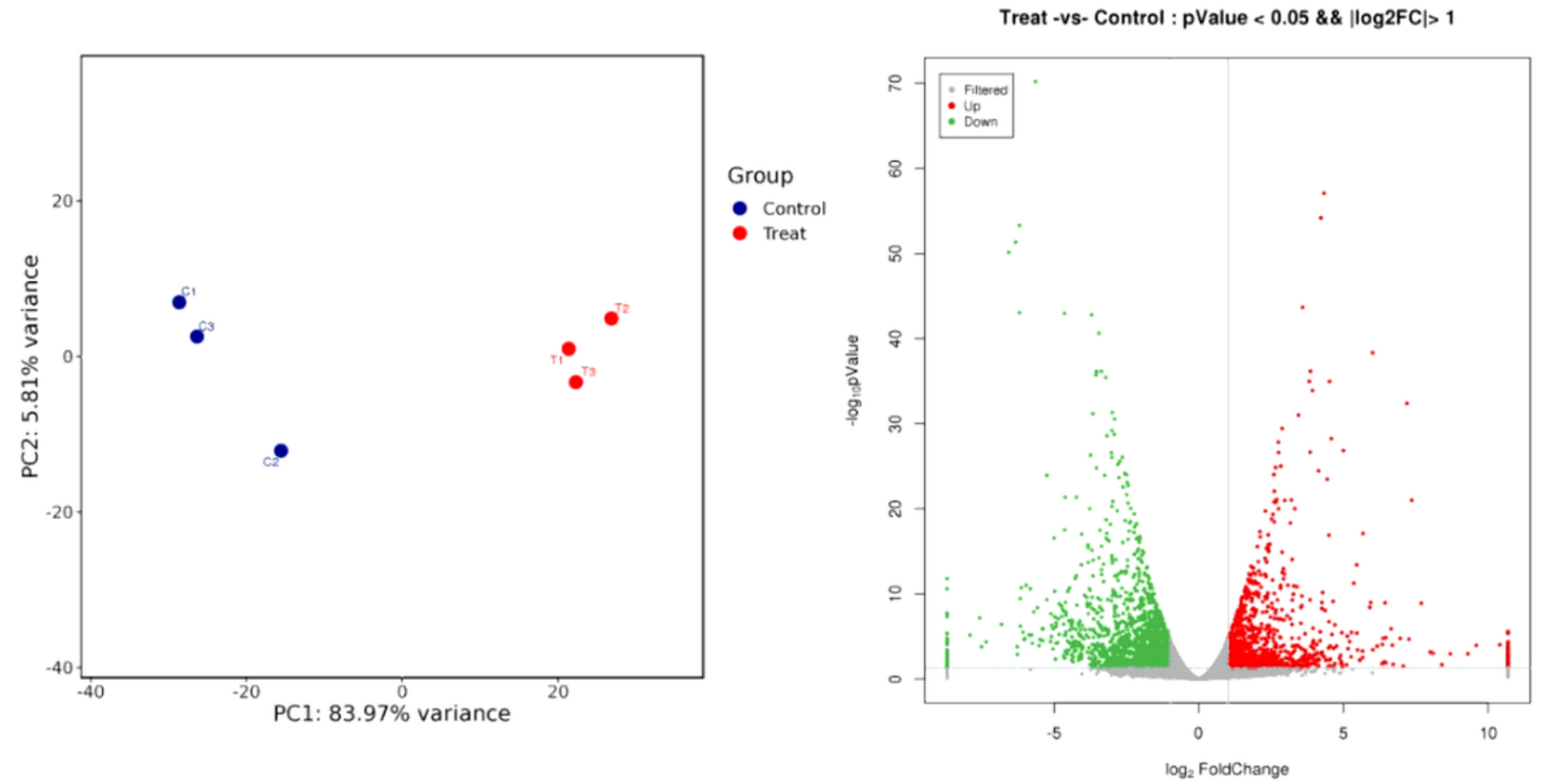

\section{Figure 2}

Two-dimensional principal component analysis (PCA) plot (a) and volcano plot (b) Note: (a) Principal component analysis (PCA) score plot. The virulent strains are indicated by blue dots labeled "Control number", while the attenuated strains are indicated by red dots labeled "Treat number." (b) The volcano plot of DEGs between Treat and Control strains. Red dots denote up-regulated significantly different Unigenes $(P<0.05$, log2 fold change $\geq 1)$; green dots denote down-regulated significantly different Unigenes $(P<$ 0.05 , log2 fold change $\leq-1)$, and gray dots denote Unigenes not significantly different. The $X$-axis shows the log2 fold change, and the $\mathrm{Y}$-axis shows the -log10 $\mathrm{P}$ value. 


\section{Gene Ontology Classification(Treat-vs-Control)}

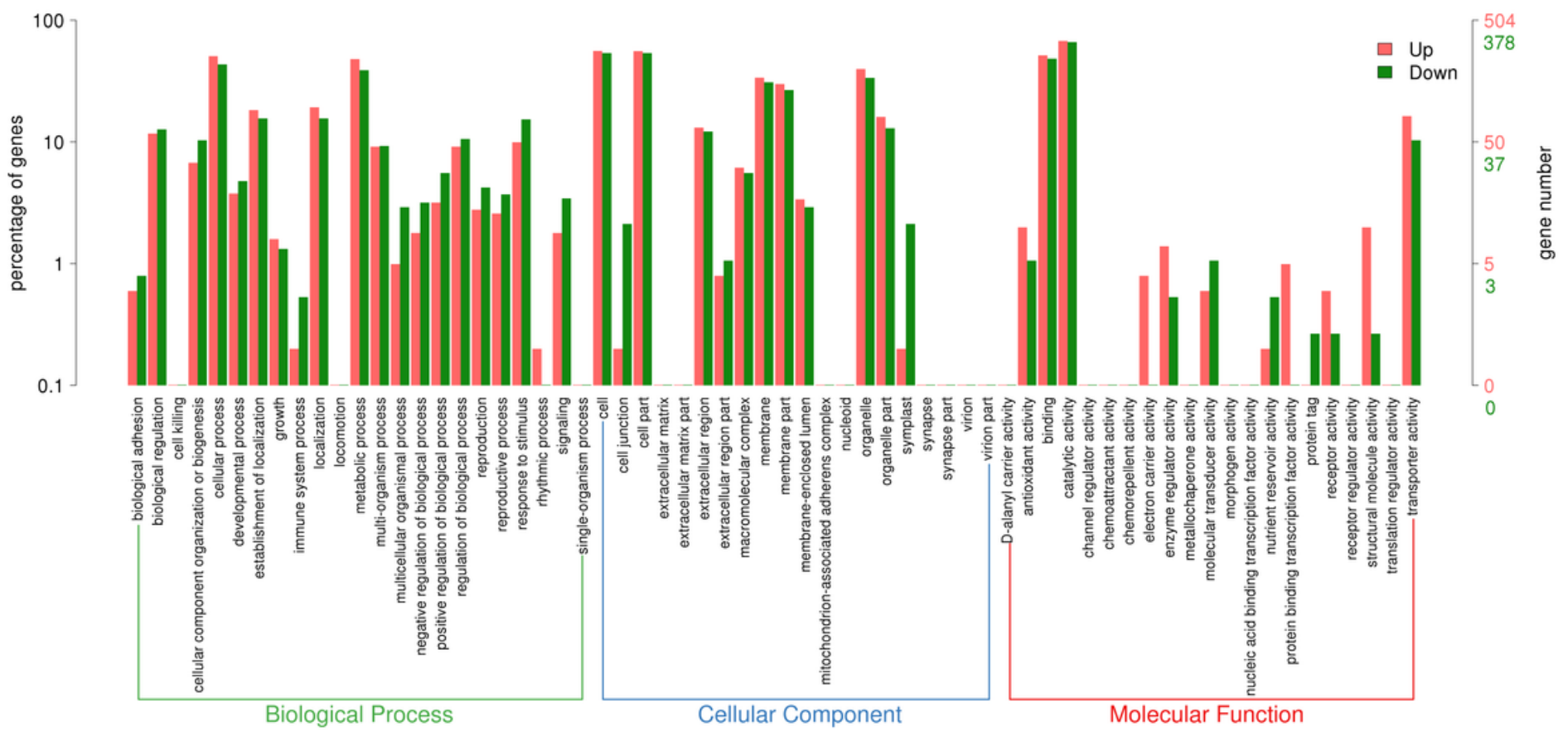

Figure 3

GO classification of DEGs $(P<0.05)$ Note: Red indicates the $G O$ sub-functional categories of up-regulated DEGs enrichment; green indicates the GO sub-functional categories of down-regulated DEGs enrichment. The X-axis lists the names of the GO sub-functional categories, and the $\mathrm{Y}$-axis is the number of genes in the corresponding sub-functional categories and the percentages. 
Treat-vs-Control(Total): KEGG Enrichment top 20

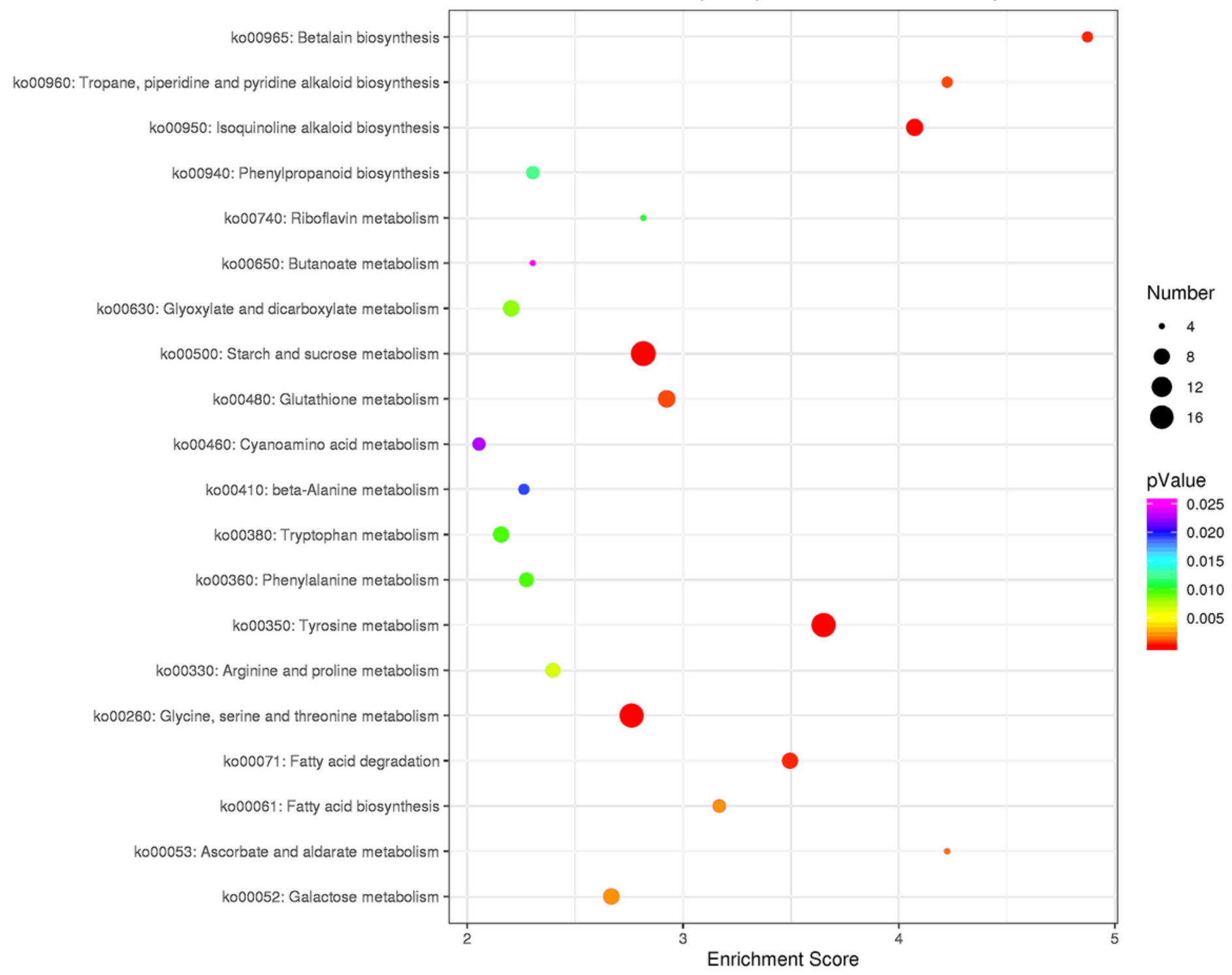

\section{Figure 4}

Top 20 enriched KEGG pathways of DEGs $(P<0.05)$ Note: The $X$-axis shows the enrichment score $(P$ value); the $\mathrm{Y}$-axis lists the enriched pathways. 